\title{
THE MATHEMATICAL COMPONENTS OF ENGINEERING EXPERTISE: THE RELATIONSHIP BETWEEN DOING AND UNDERSTANDING MATHEMATICS
}

\author{
P Kent and R Noss
}

Institute of Education, University of London, United Kingdom

SUBMITTED TO THE I.E.E. SECOND ANNUAL SYMPOSIUM ON ENGINEERING EDUCATION, LONDON, JANUARY 2002

\section{INTRODUCTION}

For a number of years, the Mathematical Sciences group at the Institute of Education has been carrying out research studies on the mathematical aspects of professional practice, looking at investment bank employees, aviation pilots, paediatric nurses and, in the research we describe here, civil and structural engineers.

The earlier research (Hoyles et al (1), Noss et al (2)) uncovered some quite sophisticated mathematical activities in practices where very little mathematics was explicitly recognised (or admitted to) by the practitioners. What emerged was a pattern of mathematics-in-use in which the mathematics of school was transformed into something rather different; numerical calculations, for example, were not just about quantities, but part of a social practice involving things; numerical relations were seen to be a part of the properties of objects rather than representations of the quantities involved. For example, nurses were observed to have a sophisticated understanding of ratio and proportion, but this understanding was situated in the tools and techniques of drug administration; that is, the nurses think about ratio not in terms of "abstract" mathematical objects, but in terms of the objects of their everyday practice.

In the case of nurses the use of mathematics is rather limited and almost completely implicit. We turned our research towards engineers because we wanted to examine a mathematically-rich professional practice where a broad range of mathematics is explicitly used. Nevertheless, explicitness does not necessarily imply that an engineer's understanding of mathematics cannot also be situated in the objects and tools of engineering practice, and elaborating this has been a major concern of our research. A further motivation for our research is the fact that in the UK, and many other countries, the mathematical education of engineers is a topic of increasing debate (see, for example Allen (3), IMA et al (4)), and we wanted to produce some data that could inform that debate in a professional practice where little previous research appeared to have been done. (There is a considerable literature about engineering design in general - see, for example, Bucciarelli (5) on the ethnographical study of practice, Vincenti (6) on the epistemology of engineering knowledge - but almost no ethnographical study on the particular roles of mathematics in design practice.)

Hence, we undertook an extensive programme of interviews and observations in a large engineering design consultancy in London, focusing on the work of civil and structural engineers. We expected to hear from engineers about rich and explicit mathematics. It was a little surprising, therefore, in our first interviews to hear comments like:

Once you've left university you don't use the maths you learnt there, 'squared' or 'cubed' is the most complex thing you do. For the vast majority of the engineers in this firm, an awful lot of the mathematics they were taught, I won't say learnt, doesn't surface again.

There is a whole lot of maths in what we do that we don't need to think about really, because other people have done it for us - getting to the simple maths that we do actually use, based on a much more complicated level of maths. The engineering discipline in the UK has certainly been set up so that we can avoid doing the complicated maths $95 \%$ of the time.

(Note: all unattributed quotations in this paper are extracts from our interviews with engineers.)

Where, then, is the complex mathematics that certainly exists in modern engineering? Throughout all aspects of engineering design, computer software has an overwhelming presence. Also, in the particular firm that we visited, there a small number of analytical specialists (a few per cent of the professional engineers employed) who act as consultants for the mathematical/analytical problems which the general design engineers cannot readily solve. (In general in structural engineering, such specialist work is often carried out by external consultants, eg. academic researchers).

Underlying the use of mathematics is the general structuring of design knowledge and practice through Codes of Practice. The Codes provide recommendations for the practical design of steel, concrete, timber, etc structures, based on a combination of accepted 
construction practice, experimental work on structures and analytical knowledge. It is worth noting that much of what is done in structural engineering practice is only partially understood at an analytical level:

Even the simplest joint between a column and a beam in a building is so complex you could spend six months analysing it. In aircraft design, you do that because it matters to reduce the size of components to the absolute safe minimum. But in buildings you approximate hugely because you have to get it done in a day, and there's nothing wrong with that, part of the art of structural design is learning how to approximate.

The Codes for structural design are not legallyprescriptive documents: there is always the liberty of not following codes, but that comes at a price. Working within the codes, design calculations will be familiar to other engineers, and to official building inspectors; but going outside could involve a lot of time and effort to produce a convincing argument that a structure will behave as predicted, and this may be in the form of a mathematical analysis that requires the input of an analytical specialist.

We have come to view the division of mathematical labour in engineering practice in terms of there being "interfaces" to pieces of mathematics which the design engineer isn't explicitly doing, but needs to understand. For example, we were told about one particular design project where:

the specialist took on the task of carrying out whatever [advanced] statistics was needed in order to give us some figures for design.... although the complicated maths, was, realistically, out of the range of my boss or me, once the specialist had worked it out then it was within the range of us to understand what he had done at some level, to be able to use the results of it.

We would like to be able to characterise in detail this kind of mathematical understanding which appears quite different from the way that engineers' use of mathematics is often talked about, especially in the context of university-level education (the "service mathematics" paradigm). In this conventional approach, the student engineer is said to learn mathematical techniques in order to "apply" them to engineering problems later on in their education, and in practice. (See Kent \& Noss (7) for further discussion on the nature of service mathematics.) Whilst this may conveniently describe engineering practice of the pre-computer era, we think it is distant from current practice, where the engineer most often uses what someone else has already applied. This raises a number of related questions. First, there is an epistemological element to the problem: what is it that gets "applied", and how is it transformed in application?
Clearly, the whole metaphor of "application" comes under scrutiny. Second, we would like to make sense of the practice of application itself; how do individuals and the communities of which they are a part, think about the mathematics involved, and how does it shape their thinking about the tools and objects of engineering design? These are big questions, and we do not pretend to have many answers. However, we will try to throw a little light on them in what follows.

\section{OBSERVING ENGINEERS IN PRACTICE}

Our observations have focused on the work of structural engineers, where we have broken down their activities into three major components: DESIGN, ANALYSIS and REVIEW - see Figure 1. We have looked for the interfaces between these activities of the structural engineers and other participants in the design process (ie. other engineers inside the company, architects and construction contractors outside).

\section{FIGURE 1 ABOUT HERE}

Of course, engineering projects run through cycles of Design and Review (ie. evaluation within the project team, or by external reviewers, at different levels of detail and formality). We have separated out Analysis (doing the calculations for a design) from Design itself: the engineers in the company we visited said that this is a strong characteristic of their particular working practice (and it appears to be common in other civil and structural engineering practices). In effect, there is a dialogue between Design:

"We need a structure that will do this, and it's going to do something like this"- the engineer does some analysis in his head to get that initial shape, and some quick calculations just to get an idea of what needs to be analysed. and Analysis:

the engineer gives that initial work to someone else, who analyses it in terms of making a model of it, getting the forces and moments out of it.

The significance of this separation from our point of view is that it introduces more interfaces (though these are "softer", within teams), and there is a further division of mathematical labour. In the words of a senior (project manager-level) engineer:

There are really only two groups of engineers who can do serious hand calculations: those within two or three years of graduation, and the lifelong analytical specialists. What most engineers retain in the long term is not the ability to execute maths, but knowing that methods exist, and who or what you can go to find a solution. Project management is about knowing what's appropriate and guiding 
people. Routine work has to be delegated, so the manager's time is focussed on what he/she does best.

Thus it is younger engineers who are performing most of the Analysis (especially computer-based), whilst older engineers handle the broader tasks of Design. In many ways, this division of work is natural, given the apprenticeship of the young engineer maturing through practical experience:

At the start of their careers, engineers are unable to deal with everything in a project, and they begin by being given straightforward things to do. They get introduced to all the aspects of a structure bit-bybit, and no one person actually ends up designing the whole structure. So, as an engineer grows up, they may no longer be using the mathematics that they started out using, they are still using the understanding that they derived earlier in their experience, and some of this is difficult to describe as to the sort of knowledge it is.

There is the germ of an epistemological insight here. In recent years it has become widespread in sociological and psychological studies of the workplace to talk about "learning by apprenticeship" and workplaces as "learning communities. That only describes part of the phenomenon however: it is crucial to examine not only the organisational structures of learning, but also the development of specific knowledge structures. Structural engineers obviously do go through a form of apprenticeship, but this involves some much less obvious restructurings of knowledge: mathematics becomes less explicit (and performed) and more "tacit" (and performed by others); the focus of the work shifts from Analysis to Design. We have found the notion of "interfaces" helpful to think about this phenomenon.

\section{MATHEMATICAL INTERFACES}

The role of interfaces appears to be more important for professional engineers than for many other users of mathematics, because the engineer cannot sign away responsibility for the artifact which he or she is designing. This means that, even in a multi-disciplinary design team, mathematical analysis cannot be a totally black box for any engineer who has to use a mathematical result, nor, as we have suggested, can it be totally open. One of our interviewees, who has particular responsibilities for training young engineers, put it as follows:

Engineers have to some sort of intellectual visualisation of what is happening inside the black box, in order to decide which is the appropriate method. If they didn't have that, we could only teach them rules, 'use this method for that type of thing...'. I would be very scared about that, the engineers have to understand what's happening inside the black box, even though they're not explicitly doing the calculations.

It seems sensible to argue that a visualisation of the inside workings of a mathematical calculation is not always required to make an informed judgement about it. The judgment can come directly from engineering understanding. One instance of this is in finite element calculations for structures, where the automatic elementgeneration algorithms can easily produce bad elements:

The software doesn't always find the best solution. When you've got really small elements there are often mistakes, because the computer gets spurious results. So there's a lot of looking at the results, finding out where things aren't performing as you would expect. You need the knowledge of how and what you expect the answer to be, so that you can see where the problems are. There is this big cycle of you make the model, check it, look at the results, check it again, make the model again if necessary.

Viewed in this way, the engineer needs to know that the software can make mistakes of a certain kind, but not necessarily how those mistakes arise in detail. Moreover, experience in using the software gives a growing appreciation of its limitations.

The designer-specialist interface appears to feature a similar aspect of understanding through use:

What's wonderful about what the specialists do is the elegance of being able to synthesise complex problems down to something very small, which can be expressed mathematically. Given the specialist's results, people can put these relationships back into their problem to investigate things. If you're worried about buckling in a particular shape of plate, the specialist can give you a set of equations, which you can adjust, change the parameters. So the maths is used as a communication tool, he's digested a situation into a model which is accessible to the general engineer, with a general mathematical background.

Since the construction Codes of Practice represent the base knowledge of normal practice, much of the work of the analytical specialist lies in interpreting the Codes (which are a compromise of the current state of understanding of practical experience and theory, and Codes in different countries often reach different compromises) and extending them into non-standard areas, but using the same "language" and style as the codes do, offering equations that the designer can make use of. This particular division of mathematical work and its communication interface has developed over many years of the firm's history, but the engineers told us that it 
is a division which is becoming too "hard" to be effective, that the company is seeking to widen the distribution of expert knowledge and diversify the forms of interaction, so that specialists are communicating not only through traditional consultations on specific problems, but also through more general internet-based discussion groups.

The role of software in engineering practice is making "understanding through use" of increasing importance. Mathematical technology makes mathematics easier to use, and this changes the culture of learning, for example about structures. Compare how engineers in the precomputer era developed an understanding for structures through the daily practice of hand calculation, and how it is happening now:

Doing hand calculations time after time gave you an understanding, but the same thing can be done on computers, say a spreadsheet. You can tune the input numbers and watch the result. Even if you don't know what's going on, so long as you can rely on the computer's calculations then you are developing an understanding. You play around with a computer model of a bridge, overstress it and watch it collapse, underbrace it and watch it vibrate. You never before had the time or the money to do that. I don't think many academics have learnt themselves that way, yet.

We will come back to the issue of modelling in the final section.

\section{INTERFACE AND ABSTRACTION}

Our use of the term "interface" is partly inspired by its use in object-oriented programming (OOP) (see Abelson \& Sussman (8)), where a separation is made between how a procedure or a piece of data is used and the details of how the procedure/data is programmed using lower-level procedures/data. The reason for this separation is the dividing up of complex programming projects into manageable sub-tasks. Each division between use and implementation is called an "abstraction barrier", and the "interface" is the means of communicating across the barrier (ie. the set of procedures which allow a programmer at the higher level to access information in the lower-level).

Thus there are programmers in a project team who are using a procedure which has been written (or indeed is yet to be written) by other programmers. Because of the abstraction barrier, they have independent tasks, but connected by the interface: the users don't need to care what happens "below the abstraction barrier", only that the implementation is complete and functional; likewise the implementers don't need to care what the users do ("abstractly") with the procedure, only that they have implemented everything "concretely" below the barrier.

Why is this interesting to us? Notice the direction of abstraction here: it is the user of the procedure who is operating more abstractly than the programmer of it, unlike the user of mathematics, the engineer, who is less "abstract" than the specialist analyst or mathematician. Is this more than a quirk of terminology? Maybe. It emphasises that the engineering design task has its own complexities of which mathematics is often a small, if crucial, component. The "royally" abstract status of mathematics in technological culture may be a distraction to thinking about what matters in practice.

The idea of "interface" emphasises the existence of areas of responsibility and what information needs, and needs not, to be communicated between those areas. Note too that in OOP, abstractions are designed for the appropriate abstraction barriers in a specific programming task, unlike in (applied) mathematics where we tend to see all abstractions as being eternally fixed into the structure of mathematical knowledge. For example, consider the fact mentioned above that the established designer-specialist interface in the engineering firm is becoming unsatisfactory, so the abstraction barrier and its communication interface are being redesigned.

\section{A “FEEL" FOR STRUCTURE AND GEOMETRY}

We hinted earlier at the "situated" nature of engineers" understanding of mathematics, and we think a key example of that for structural engineers is to do with the "geometry" of structures. Geometry was mentioned repeatedly in our interviews as a key element of structural understanding:

Geometry is enormously important. For example, its relation to structural behaviour: the bending moment in a beam being a significant shape - it's a parabola, and not just any old parabola, but one that represents the structural behaviour. Similarly for the catenary, a curve that corresponds to the structural behaviour of a chain. Historically, this began with things like Hooke's analysis of the hanging chain as an inverted stable arch, and it goes on through the development of the I-beam as the most efficient way of using material, the largest second moment of area per weight of material. The geometry of an I-beam is something fundamentally structural, embodied within it is the structural concept called second moment of area. Or, in a complex three-dimensional tent, there's the equilibrium of forces in three dimensions. And that's not Platonic geometry, it is structural geometry. 
The engineer can use mathematics to carry around in a very compact form the shapes and magnitudes of the deformations of structural elements when loads are applied: a beam loaded in a certain way takes on a parabolic shape, it's "something $\mathrm{x}$-squared over something". Understanding is situated in the sense that a structural engineer tends to think about the "standard" plane curves for what they mean in structural terms. Although they may simultaneously know (and have certainly been exposed to) a large amount of mathematics, the "active" meanings are structural. There is no need, most of the time, to isolate out a "pure" mathematical meaning, but it remains important to know where analytical results come from, knowing about the "other side" of the mathematical interface (cf. section 3 above.)

Interestingly, the engineers tended to talk about structural geometry in relation to qualitative understanding of structures:

Qualitative understanding is based on sets of rules that are very clearly based on the mathematics of how forces and elements are interacting between each other. You have to draw the structural diagrams, and you're looking for clues, and some of those clues come from the maths you've done. You couldn't draw the diagrams without having done that.

This sense of qualitative is entwined with the notion of Design, in contrast to the quantitative calculations of Analysis (which are now largely in the realm of computer software). Another term for qualitative understanding often used by engineers is "structural feel", which emphasises that it is something intuitive. For example, the expertise of the superlative structural engineer Peter Rice was compared to that of a great pianist: "he plays with closed eyes, he doesn't look at the piano; he knows the music so well, he knows the mechanics and feelings so well that he doesn't care" (Piano (9)).

The interesting thing for us is that this is an intuition that does not come entirely naturally, it is learnt by experience, and some of that experience is learning mathematics formally at school and university, and using mathematics in engineering practice.

\section{IMPLICATIONS FOR EDUCATION}

Our research has not been explicitly concerned with the relationships between engineering education and practice, but it is appropriate here to make a few comments on this point, which are mostly confirmations of points that have already been made in the engineering education literature.

The first point concerns the nature of mathematical understanding for engineers. We have suggested that the balance between explicit analytical skills and "qualitative" appreciation of mathematical models is radically shifting as mathematical technology becomes increasingly ubiquitous. According to a design engineer that we interviewed:

The [construction] industry is constantly effectively removing mathematics from structural design as far as it can. Increasingly, designs are standardised for the sake of the production process, methods are codified/standardised and more analytical work is done through a computer, often by people who rely on others to have checked the methods. We do however still do calculations, and check the results of our analyses, and this of course involves some mathematics, but at a fairly basic level. For example, I can't remember when I last had to differentiate or integrate anything.

The consequences of this for undergraduate education have been recognised for some time, for example:

"who, in practice nowadays, would conduct an elastic analysis of a single-bay portal frame other than by feeding it into the office program?" Yet "university libraries contain shelves of structural textbooks devoted to complex and impenetrable hand methods for analyzing such structures". The student really needs to know how to represent the key features of a real structure within a manageable computer analysis; i.e., how to "model" the structure. ...Courses contain little in this area at present. Instead, modelling skills are developed in an ad hoc fashion during the early years of practice. Such teaching requires exposure to a graded series of examples linked to carefullyconceived methods of assessment, not lectures on the matrix stiffness method and techniques for solving simultaneous equations. Allen (3)

The concern for modeling has also been noted by the engineering educators Bissell \& Dillon (10), who are careful to point out that mathematical models are not simple "applications" of abstract, context-free mathematical techniques:

The aims and purposes of engineers are not those of mathematicians. There is a focus on explanation and design, in contrast to mathematical structure and rigour. ... Different communities of practice lead to different ways of talking and doing, even when they are dealing apparently with the "same thing". Tacit skills learnt by experience in engineering may not integrate well with the formal skills laid down in mathematics courses. Bissell \& Dillon (10)

There is not yet a generally-accepted term for the kind of mathematical understanding that modelling represents. It is a knowledge not of mathematics but about mathematics, 
at a meta-level. A term that has been proposed is "mathematical literacy", defined (for example) by IMA et al (4) as something complementary to having mathematical manipulation skills, as an ability to communicate ideas, based on an understanding of the ways in which ideas can be expressed.

We are conscious that our research can only inform curriculum reform to a limited extent, not least since undergraduate curricula are so politicised (with frequent tensions between academic knowledge domains), and slow to change. Perhaps the most important message that we want to give based on our findings (and also earlier work that we have ourselves done in undergraduate mathematics, see Kent \& Noss (5)), is an epistemological one: the challenge facing undergraduate service mathematics is not simply about students doing more or less mathematics, but is about questioning the interfaces between engineering and mathematical knowledge, as differently experienced by practicing and student engineers.

\section{ACKNOWLEDGEMENT}

The research project "Mathematical Components of Engineering Expertise" was funded February - December 2001 by the United Kingdom Economic and Social Research Council, grant number R000223420.

\section{REFERENCES}

1. Hoyles, C, Noss, R and Pozzi S, 2001, "Proportional Reasoning in Nursing Practice", Journal for Research in Mathematics Education, 32, 14-27

2. Noss, R, Hoyles, C and Pozzi, S, "Abstraction in Expertise: A Study of Nurses' Conceptions of Concentration", submitted to Journal for Research in Mathematics Education

3. Allen H G, 2000. "Civil and Structural Engineering Education in the 21st Century: A review of papers presented at the conference", The Structural Engineer, $\underline{78}$, $17,17-20$

4. I.M.A. et al, 1995, "Mathematics Matters in Engineering". Institute of Mathematics and its Applications, Southend-on-Sea, U.K.

5. Bucciarelli L, 1994, “Designing Engineers”, MIT Press

6. Vincenti W G, 1991, "What Engineers Know and How They Know It: Analytical studies from aeronautical history", Johns Hopkins University Press
7. Kent $\mathrm{P}$ and Noss R, 2001, "Finding a Role for Technology in Service Mathematics for Engineers and Scientists". In: D Holton et al. (eds.), "The Teaching and Learning of Mathematics at University Level: An ICMI Study", Kluwer Academic Publishers

8. Abelson H and Sussman G J, 1996, "Structure and Interpretation of Computer Programs", MIT Press

9. Piano, R, 1992, "Introduction to the Royal Gold Medal Address", Royal Institute of British Architects Journal, September 1992

10. Bissell C and Dillon C, 2001, "Telling Tales: Models, Stories and Meanings", For the Learning of Mathematics, $20,3,3-11$ 
FIGURE 1

A schematic view of the participants in a building project, and their lines of interaction.

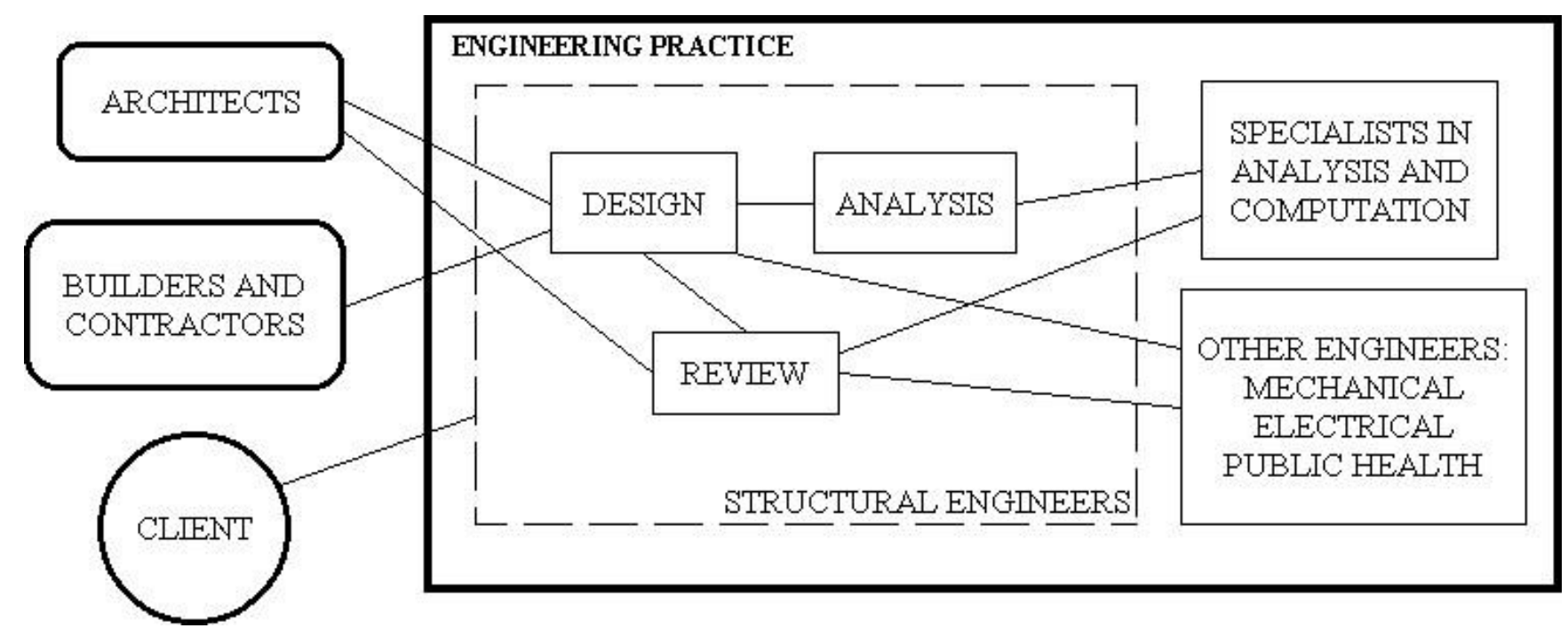

